\title{
Strain weakening enables continental plate tectonics
}

Frédéric GUEYDAN (1), Jacques PRÉCIGOUT (2) and Laurent G.J. MONTESI (3)

(1) Géosciences Montpellier, Université de Montpellier 2, CNRS UMR 5243, Montpellier, France

(2) Institut des Sciences de la Terre d'Orléans, Université d'Orléans, CNRS UMR 7327, Orléans, France

(3) Department of Geology, University of Maryland, College Park, MD 20742, USA

Corresponding author: frederic.gueydan@um2.fr, T: 0033(0)467144593, F: $0033(0) 467143642$

\section{Abstract}

Much debate exists concerning the strength distribution of the continental lithosphere, how it controls lithosphere-scale strain localization and hence enables plate tectonics. No rheological model proposed to date is comprehensive enough to describe both the weakness of plate boundary and rigid-like behaviour of plate interiors. Here we show that the duality of strength of the lithosphere corresponds to different stages of microstructural evolution. Geological constraints on lithospheric strength and large strain numerical experiments reveal that the development of layers containing weak minerals and the onset of grain boundary sliding upon grain size reduction in olivine cause strain localisation and reduce strength in the crust and subcontinental mantle, respectively. The positive feedback between weakening and strain localization leads to the progressive development of weak plate boundaries while plate interiors remain strong. 


\section{$1 /$ Introduction}

The extrapolation of laboratory flow laws to geological scale suggests a complex layering of brittle and ductile layers within the continental lithosphere (Brace and Kohlstedt, 1980; Sawyer, 1985). For classical continental geotherm, the upper lithospheric mantle is expected to be brittle and support high stresses. Many analogue and numerical experiments indicate that such a rheological layering is important to reproduce first-order patterns of lithosphere deformation (Brun, 1999; Burov and Yamato, 2008). In particular, the presence of a brittle uppermost mantle is needed to explain strain localisation at lithospheric scale (Buck, 1991; Gueydan et al., 2008).

However, recent geophysical studies question this classical view of the continental strength layering. Based on earthquakes distribution and elastic thicknesses of the continental lithosphere, including cratons, it has been proposed that the uppermost mantle could behave as ductile instead of brittle (Déverchère et al., 2001; Jackson, 2002; Maggi et al., 2000). However, the mechanical stability of cratons requires that the uppermost mantle supports high stresses (Burov, 2010). In addition, the post-seismic displacement field, i.e., the pattern of deformation at the surface of the Earth within weeks to years following an earthquake, suggests that the deep crust is stronger than the lithospheric mantle. (Bürgmann and Dresen, 2008; Thatcher and Pollitz, 2008). Note however that post seismic displacement field may also result from a complex combination of poro-elasticity and fault creep in the seismogenic layer and viscous flow in the lower crust (Barbot and Fialko, 2010). In this case, it may not be used to constrain strength ratios between the ductile crust 
and lithospheric mantle. Finally, the recent discovery of non-volcanic tremors, i.e., long duration seismic events with small amplitudes, below the San Andreas fault suggests a zone of localized and easily modulated faulting in the lower crust (Nadeau and Guilhem, 2009; Thomas et al., 2009). Assuming high temperatures in plate boundaries such as the San Andreas Fault System does not solve this conundrum, as that would imply both a weak mantle and a weak crust.

The above geophysical data question the classical view of continental strength layering and suggest a weak continental lithosphere at plate boundaries. To date, no rheological self-consistent model accounts for both the weakness of plate boundary, which is a prerequisite of plate tectonics, and rigid-like behaviour of plate interiors. A new definition of the continental lithosphere strength is needed to reconcile the apparent contradiction between 1) the mechanical prerequisite of a strong brittle mantle to trigger lithosphere-scale strain localisation, and 2) the low lithosphere strength inferred in actively deforming region, especially in the mantle. Although it may be argued that the presence of fluid and/or shear heating can trigger weak plate boundaries (Jackson, 2002; Thielmann and Kaus, 2012), the existence of long-lived lithosphere-scale inherited weak zone (Tommasi et al., 2009) suggests that a structural origin for the weakness of plate boundaries is also necessary. Crucially, lithospheric strength must decrease with increasing strain. We present here a quantitative model of strain-dependent lithospheric strength derived from large-strain numerical experiments and guided by field observations that constrain the structural evolution of rocks at various depths in the lithosphere.

\section{2/ Geological constraints}


Many processes have been suggested as the origin of strain weakening that triggers strain localization in both the crust and mantle (Poirier, 1980; White et al., 1980; Montési and Zuber, 2002; Regenauer-Lieb and Yuen, 2004). To date, shear heating has probably received the most extensive theoretical treatment (Brun and Cobbold, 1980; Fleitout and Froidevaux, 1980; Regenauer-Lieb and Yuen, 1998; Kaus and Podladchikov, 2006; Crameri and Kaus, 2010). However, field observations indicate that metamorphic reactions, fluid infiltration and grain size reduction play a crucial role in enabling shear localization (Poirier, 1980; Park et al., 2006; Wintsch et al., 1995; Warren et al., 1996; Gueydan et al., 2003; Drury, 2005; Gerbi et al., 2010; Toy et al., 2010; Platt and Behr, 2011; Rennie et al., 2013; Sullivan et al., 2013). It is thus important to characterize the rheological effect of these processes. We will show that geologically-constrained changes in rock texture are able to explain the apparent weakness of the continental lithosphere and the presence of a strong lower crust above a weak mantle at active plate boundaries. Field and laboratory constraints on weakening processes are summarized here.

In the brittle crust, lubrification of fault zone is achieved by nucleation of new mineral (mica, talc; Holdsworth, 2004). The development of foliated cataclasis enriched in mica leads to strain weakening of fault zone through a decrease of the friction coefficient from 0.6 to 0.1 with strain (Collettini et al., 2009; Faulkner et al., 2010). In the ductile crust, the progressive development of layering (shear zone and/or foliation) enriched in mica is also a characteristic of the midcrust and is related to intense weakening the rocks (Gueydan et al., 2004; Gueydan et al., 2003; Montési, 2013; Wintsch et al., 1995). Here, we used a two-level mixing theory (Montési, 2007), see Appendix for more details) to calculate the strength of the midcrust as a function of the layering degree, $f$, which increases from 0 (granitic 
protolith) to 1 (pure phyllonite) upon deformation. The weakening associated with the development of layering is greatest a low temperature $\left(300^{\circ} \mathrm{C}\right)$ while hardening is expected at temperatures higher than $500^{\circ} \mathrm{C}$ (Fig 1A). This reflects differences in dislocation creep activation energy between mica and quartz/feldspar (Table 1); the mica is much weaker than quartz at low temperature but retains its strength while quartz and feldspar become much weaker than mica at high temperature (Kronenberg et al., 1990). Furthermore, mica breaks down or melts at high temperature, making the layer development process irrelevant in the lower crust. Therefore, layering-induced weakening can only occur at midcrustal depth where temperature is below $500^{\circ} \mathrm{C}$. Other weakening processes are expected in the deep crust, such as shear heating (Thielmann and Kaus, 2012), but are disregard here in order to focus on strain weakening related to microstructural evolution.

In naturally deformed mantle rocks, strain localisation is typically associated with grain size reduction and a switch from grain size-insensitive creep to grain sizesensitive creep (Drury, 2005). Recent observations on natural samples highlighted the importance of the grain-size-dependent dislocation-accommodated grain boundary sliding (disGBS) of olivine as controlling the rheology of mantle shear zone (Précigout et al., 2007; Warren and Hirth, 2006). Deformation experiments and numerical investigations have also shown that disGBS could promote strain localisation during dynamic recrystallization (Hirth and Kohlstedt, 2003; Précigout and Gueydan, 2009). Indeed, under conditions where disGBS constitutes the dominant deformation mechanism of peridotite, i.e., at temperature lower than $800^{\circ} \mathrm{C}$, grain size reduction is associated with a significant drop of strength ((Précigout et al., 2007), see Appendix for more details). This amount of strain weakening increases 
with decreasing temperature and does not occur for temperature larger than $800^{\circ} \mathrm{C}$.

(Fig 1B, (Précigout and Gueydan, 2009)).

\section{3/ Large strain numerical experiments}

The rheologies and weakening processes described above are implemented in large strain numerical experiments to quantify the relationship between strain and strength at various depths in the lithosphere. Because of the non-linear behaviour of the ductile crust and mantle, numerical modelling is required to capture the interplay between weakening and strain localization and to quantify the strength evolution of the ductile layers of the continental lithosphere. By contrast, strain weakening in the brittle crust simply consists of a change of the friction coefficient from 0.6 to 0.1 due to fabric development (Collettini et al., 2009; Faulkner et al., 2010).

\section{1/ Numerical results}

The numerical experiments follow the evolution of a one-dimensional section of a ductile rock undergoing horizontal simple shear to large strain at a given temperature (Fig. 2). Numerical methods used here for the large strain experiments are very similar to those used in previous studies where techniques for large strain approximation and numerical details of the finite element code SARPP can be founded (Gueydan et al., 2004; Gueydan et al., 2008). A week seed of $100 \mathrm{~m}$ and with an initial viscosity of 0.9999 times the viscosity of the host rock is imposed in the center of the model in order to initiate strain localisation. Figure 2 shows model results - extruded to two dimensions to ease reading - for a $100-\mathrm{km}$ wide section of crustal or mantle material sheared by a boundary displacement of $230 \mathrm{~km}$ for an 
overall strain 2.3. In crustal rocks (Fig. 2A), strain localisation occurs at $300^{\circ} \mathrm{C}$ and $400^{\circ} \mathrm{C}$, resulting in a lithospheric-scale shear zone where the local strain reaches 100. The amount of weakening (Fig. 1A) and hence the accumulated strain within the shear zone is maximum at $300^{\circ} \mathrm{C}$. Strain localisation results from the progressive development of layering that leads to a decrease in material strength and an increase in strain rate within the shear zone (Gueydan et al., 2004; Gueydan et al., 2003; Montési, 2007). The crustal shear zones are marked by a degree of layering that progressively tends toward 0.9 with increasing strain while the country rocks strength does not evolve. The shear zone thickness increases with temperature to accommodate the same boundary displacement. For temperature larger than $500^{\circ} \mathrm{C}$, the increase in layering leads to strengthening of the crustal rocks and no strain localisation.

A similar behaviour is predicted for the mantle. In this case, viscosity decreases by more than two orders of magnitude at $600^{\circ} \mathrm{C}$, leading to the formation of a narrow mantle shear zone (Fig. 2B). Strain localisation results from a weakening induced by the dominance of disGBS during dynamic grain size reduction (Fig 1B and 2B, (Précigout and Gueydan, 2009)). Strain localisation does not develop for mantle temperature larger than $800^{\circ} \mathrm{C}$, when disGBS is no longer the dominant deformation process (Fig 1B). In this case, grain size evolution does not induce weakening, and the shear zone viscosity remains close to the initial value.

Figure 3 presents the evolution of the effective viscosity in the developing shear zone in the mid-crust or in the subcontinental mantle. In crustal rocks (Fig. 3A), strain localises at temperatures between $300^{\circ} \mathrm{C}$ and $400^{\circ} \mathrm{C}$. It results from the progressive development of layering that decreases material strength by more than a factor of 10 at strains larger than 1 . The asymptotic value corresponds to the 
complete layering, and hence no further weakening processes can lead to a later drop of strength. At higher temperature, the drop of viscosity is less important and even not present for temperature larger than $500^{\circ} \mathrm{C}$. In mantle rocks (Fig $3 \mathrm{~B}$ ), strain localisation induced by the dominance of disGBS leads to a drop of viscosity by more than one order of magnitude at $600^{\circ} \mathrm{C}$. The asymptotic value is also reached after strain larger than 1. At this stage, grain size reduction stops and no weakening is expected in the mantle shear zone at larger strain. Strain localisation does not develop for mantle temperature larger than $800^{\circ} \mathrm{C}$, when disGBS is no longer the dominant deformation process (Fig 1B). In this case, grain size evolution does not induce weakening, and the shear zone viscosity remains close to the initial value.

\section{2/ Strain weakening}

Strain localization is associated with a decrease of effective viscosity from an initial value $\eta_{0}$ to an asymptotic value $\eta_{\infty}$ in ductile shear zones or a reduction of strength from $\sigma_{0}$ to $\sigma_{\infty}$ in the brittle crust. The effective viscosity is defined by the ratio between the shear stress and the overall strain rate that is here $10^{-15} \mathrm{~s}^{-1}$. Figure 4 summarizes these results by presenting a measure of strain weakening, $\alpha$, as a function of depth, where $\alpha=1-\left(\sigma_{\infty} / \sigma_{0}\right)$ or $\alpha=1-\left(\eta_{\infty} / \eta_{0}\right)$ in brittle or ductile layers of the crust. For the upper crust, a change from 0.6 to 0.1 implies a strain weakening of $83 \%$ related to the progressive development of foliated cataclasites (Fig. 4). Weakening is even more intense in the middle crust where, for example, viscosity decreases from $2 \times 10^{23}$ Pa.s to $10^{22}$ Pa.s and implies a strain weakening of $95 \%$ (Fig 4). These relative high values of viscosity compared to what is inferred in most plate boundaries (Thatcher and Pollitz, 2008, Bürgmann and Dresen, 2008) are due to the selected value of mean strain rate that would however not change the quantification 
of strain weakening, since it is a ratio of viscosities. Strain weakening remains close to $90 \%$ in the crust at temperature lower than $400^{\circ} \mathrm{C}$ and then progressively decreases to vanish at $500^{\circ} \mathrm{C}$. No strain weakening is expected in the deep crust, since shear heating is disregarded. In the lithospheric mantle, strain weakening reaches again $90 \%$ for temperature lower than $700^{\circ} \mathrm{C}$ and then decreases to vanish at $800^{\circ} \mathrm{C}$ (Précigout and Gueydan, 2009).

The evolution of strength predicted by our numerical models as a function of strain can be approximated by an exponential relationship as follow:

$$
\sigma(\varepsilon)=\sigma_{\infty}+\left(\sigma_{o}-\sigma_{\infty}\right) \exp \left(-\varepsilon / \varepsilon_{c}\right)(\text { eq. } 1)
$$

in which $\varepsilon$ is the strain and $\varepsilon_{c}$ is a parameter that represents the characteristic strain over which the fabric of deforming rocks changes according layering development or grain size reduction. The large strain experiments (Figs. 2-3) are represented well with this general form and with a critical strain of $\varepsilon_{c} \sim 0.5$ for both the ductile crust and the ductile mantle. For seek of simplicity, the critical strain for the brittle crust is also set to 0.5 . However, note that the critical strain depends on the poorly constrained kinetics of metamorphic reaction for the crust and of grain size reduction for the mantle that remain to be quantified by large strain experimental deformation in laboratory.

Combining eq 1 with the definition of the strain weakening factor $\alpha$ yields an unified description of the lithosphere strength that becomes a function of strain $\varepsilon$, temperature $T$, and strain rate $'$ :

$$
\sigma(\varepsilon, T, \dot{\varepsilon})=\sigma_{o}(T, \dot{\varepsilon}) \cdot\left\{1+\alpha\left[\exp \left(-\varepsilon / \varepsilon_{c}\right)-1\right]\right\} \text { at a given } \dot{\varepsilon} \text { (eq. 2) }
$$

The initial strength $\sigma_{o}(T, \dot{\varepsilon})$ is defined in the ductile layers for the protolith (granitic composition or an olivine aggregates in the crust or the mantle, respectively) according to the classical strain-rate and temperature sensitive flow law such as 
dislocation creep (Appendix section). In the brittle upper crust, the initial strength obeys the Mohr-coulomb failure criterion. It is insensitive to temperature and strain rate but depends on confining pressure, and therefore depth. The values of the strain weakening coefficient $\alpha$ are those shown on Figure 4 and therefore are a function of depth.

\section{4/ Continental lithosphere strength profiles during strain localization}

The unified model of strength as a function of strain, strain rate and temperature (Eq. 2) is now used to characterize the evolution of the continental lithosphere strength during progressive strain localization. The development of plate boundary is represented by an increase in strain rate from $10^{-17} \mathrm{~s}^{-1}$ to $10^{-13} \mathrm{~s}^{-1}$ coeval with a strain increase from 0 to 2 (Fig. 5). The continental geotherm is such that the Moho temperature is $600^{\circ} \mathrm{C}$. We ignore the possibility of shear heating to focus on microstructural changes that accompany localisation.

At low strain rate and strain (Fig. 5A), the continental strength profile shows a classical mechanical layering, with two high strength layers: the upper crust and the uppermost mantle. No brittle mantle is predicted at such a low strain rate. As strain rate increases to $10^{-15} \mathrm{~s}^{-1}$ and strain reaches 1 , two contrasting features appear (Fig. 5B). Strength decreases in the upper crust, mid-crust and the uppermost mantle where strain weakening is expected because of brittle faulting, layering development and grain size reduction coupled to disGBS, respectively (Fig. 5B). By contrast strength increases markedly in the deep crust where no strain weakening is suspected. The same features are strongly enhanced at the final strain rate and strain $\left(10^{-13} \mathrm{~s}^{-1}, \varepsilon=2\right.$, Fig. $\left.5 \mathrm{C}\right)$. Overall, strain weakening is associated with a 
decrease in lithosphere strength as strain rate increases to counteract the strength increase otherwise produced by the fundamental strain-rate hardening characteristics of ductile flow laws.

The positive feedback between strain localization and weakening leads to a reversal in strength stratification of the lithosphere. The lower crust, which is initially the weakest layer, becomes the strongest, while the upper mantle and upper to middle crust become the weakest levels. Thus it is possible to reconcile the apparently contradictory evidence for a high strength upper mantle needed to develop plate boundaries and the evidence of a strong lower crust in active deformation zones.

\section{5/ Discussion and conclusion}

The strength model developed above shows that actively deforming regions such as plate boundaries, are characterized by a weak upper-mid crust and weak lithosphere mantle surrounding a high strength deep crust (Fig. 5C), where the zones of weakness are related to microstructural evolution. The weakness of continental plate boundaries is consistent with geophysical observations that suggest very low elastic thickness in these regions (Audet and Bürgmann, 2011).

Strain weakening in the ductile middle crust permits mechanical decoupling between lower crustal flow and upper crust faulting, which is essential to promote localised faulting and large displacement along faults (Lavier and Buck, 2002; Huismans and Beaumont, 2003; Nagel and Buck, 2004; Schueller et al., 2005; Schueller et al., 2010). The absence of weakening in the deep crust yields to a progressive increase of its strength during strain localization so that it becomes the strongest level of the lithosphere, as is indicated by post-seismic creep 
measurements in California (Bürgmann and Dresen, 2008; Thatcher and Pollitz, 2008).

The long-term strength of the continental lithosphere described here may be further modified by interaction with the seismic cycle. Figure 6 proposes a structural interpretation of the character of seismicity at a continental strike slip fault like the San Andreas Fault. Major earthquakes take place in the seismogenic upper crust. Immediately below that level, the localizing midcrust, which acts as a decoupling layer, constitutes a region where fluid-rock interaction is dominant, allowing metamorphic reaction, development of layering, and related weakening (Holdsworth, 2004). In this layer, weakening would generate relatively narrow ductile shear zones where transient changes in pore fluid pressure and shear stress may induce microseismicity (Rolandone et al., 2004; Gratier and Gueydan, 2007).

Post-seismic deformation following large earthquakes is detected at large distance from the main shock, implying the presence of a strong layer at depth most likely in the lower crust (Freed et al., 2007; Lindsey and Fialko, 2013). Non-volcanic tremors at 20 to $40 \mathrm{~km}$ depth below the San Andreas fault (Nadeau and Dolenc, 2005; Thomas et al., 2012) suggests that shear failure is possible within the dominantly creeping deep crust. The easy modulation of tremors activity in response to different loading (Shelly and Hardebeck, 2010, Thomas et al., 2012) furthermore implies that the lower crust is very weak and close to failure. Transient loading during earthquakes and slow slip events in the mid-crust and in the upper mantle may increase pore fluid pressure and lead to shear failure in the otherwise ductile lower crust, generating tremor activity (Fig. 6). Further studies, combining geological, mechanical, and seismological approaches, are needed to unravel the precise 
mechanics of transient loading, fluid-rock interaction, pore fluid pressure and shear failure.

Finally, the mantle opposes little resistance to deformation as evidenced by the absence of earthquakes in the mantle and also postseismic displacements pattern. Our rheological model supports the idea of a broad mantle shear zone, probably $50 \mathrm{~km}$ wide below the fault zone (Freed et al., 2007; Fig 6). The exact thickness of this mantle shear zone would depend on the degree of heterogeneity (Vauchez et al., 2012), the amount of coupling between crustal deformation and mantle deformation (Schueller et al., 2010) and the amount of weakening within the lithospheric mantle. The rheological model developed here provides the foundation for new study of shear zone development that would unravel the expected structure of continental fault zones at depth.

\section{6/ Acknowledgements}

We thank Roland Bürgmann, an anonymous reviewer, and editors Evgenii Burov and Laurent Jolivet for their constructive comments on this manuscript. LGJM was supported by grant NASA PGG NNX10AG41G.

\section{7/ Appendix: Strain-dependent rheologies}

\section{1/ Midcrust rheology}

The crustal protolith is assumed to have a granite-like mineral assemblage, constituted of $40 \%$ quartz, $50 \%$ feldspar, and $10 \%$ mica homogenously distributed throughout the rock. The strength of the protolith, $\sigma_{\text {protolith, }}$ is the weighted sum of the 
strength of its constitutive minerals assuming that geometrical incompatibilities in a homogeneous rock force all the phases to adopt the same strain rate:

$$
\sigma_{\text {protolith }}=0.4 \sigma_{\text {quartz }}+0.5 \sigma_{\text {feldspar }}+0.1 \sigma_{\text {mica }} \text { (eq. 3) }
$$

where $\sigma_{\text {quartz }}, \sigma_{\text {feldspar }}$ and $\sigma_{\text {mica }}$ are defined by the experimentally calibrated flow such as the dislocation creep

$\dot{\varepsilon}=A \exp \left(\frac{-Q}{R T}\right) \sigma^{n}$, (eq. 4)

where $A, Q$, and $n$ are the pre-exponential constant, the activation energy and the stress exponent and depend on the rock type (Table 1).

After large deformation, the protolith becomes a mylonite, with higher mica content due to fluid-rock interactions and a strain-induced layered structure. If reaction reaches completion, the strength of the shear zone would be given by the rheology of mica:

$$
\sigma_{\text {shear zone }}=\sigma_{\text {mica }} \quad(\text { eq. } 5)
$$

At intermediate stages, a two-level mixing theory (Montési, 2007) is used to estimate the strength of the aggregate as a function of the degrees of layering $f$ :

$$
\sigma=(1-f) \sigma_{\text {protolith }}+f \sigma_{\text {shear zone }} \text { (eq. 6) }
$$

Although a pure mylonite would have $f=1$, we consider the final stage of evolution to be $f=0.9$ to avoid strong numerical instabilities that arise when weakening is too intense.

\section{2 / Mantle rheology}

Based on field observations in the Ronda peridotite (southern Spain) and the experimental data of Hirth and Kohlstedt (2003), Précigout et al. (2007) proposed a strain-dependent mantle rheology in which the overall strain rate $\dot{\varepsilon}$ is the sum of four ductile deformation mechanisms: dislocation creep $\left(\dot{\varepsilon}_{r}\right)$, diffusion creep $\left(\dot{\varepsilon_{d}}\right)$, disGBS 
$\left(\dot{\varepsilon}_{g}\right)$ and exponential creep $\left(\dot{\varepsilon}_{e}\right)$ (Hirth and Kohlstedt, 2003; Drury, 2005; Précigout et al., 2007). Each mechanism contributes to the bulk strain rate $\left({ }^{\circ}\right)$ of an olivine aggregate according to:

$\dot{\varepsilon}=\dot{\varepsilon}_{r}+\dot{\varepsilon}_{d}+\dot{\varepsilon}_{g}+\dot{\varepsilon}_{e} \quad$ (eq. 7)

where the corresponding flow laws are:

$\dot{\varepsilon}_{r}=A_{r} \cdot \exp \left(-\frac{Q_{r}}{R T}\right) \sigma^{n_{r}} \quad$ (eq. 8)

$\dot{\varepsilon}_{d}=A_{d} \cdot \exp \left(-\frac{Q_{d}}{R T}\right) \sigma^{n_{d}} d^{-m_{d}}$ (eq. 9)

$\dot{\varepsilon}_{g}=A_{g} \cdot \exp \left(-\frac{Q_{g}}{R T}\right) \sigma^{n_{g}} d^{-m_{g}}$ (eq. 10)

and

$\dot{\varepsilon}_{e}=A_{e} \cdot \exp \left(-\frac{Q_{e}}{R T}\right)\left(1-\sigma / \sigma_{p}\right)^{n_{e}} \quad$ (eq. 11)

In the above equation, $\sigma$ is the stress [MPa], $d$ is the grain size $[\mu \mathrm{m}], T$ is temperature $[K], R$ is the gas constant, and $A, Q$ and $n$ are the material parameters indicating the pre-exponential constant, the activation energy and the stress exponent for each mechanism identified by their respective indexes ( $r=$ Dislocation creep; $d=$ Diffusion creep, $g=$ DisGBS creep and e=exponential creep). Finally, $m_{d}, m_{g}$, and $\sigma \square$ are respectively the grain size exponent for diffusion creep and disGBS, and a constant parameter for the exponential creep (Peierls stress; Goetze, 1978) (Table 1). Grain size reduction can only occur within grain size/stress domains where dislocation creep is effective enough, i.e., dislocation creep and disGBS, up to the boundary of the diffusion creep field, where we assume that only grain growth can occur.

\section{References}


Audet, P. and Bürgmann, R., 2011. Dominant role of tectonic inheritance in supercontinent cycles. Nature Geosciences, 4: 184-187.

Barbot, S. and Fialko, Y., 2010. A unified continuum representation of post-seismic relaxation mechanisms: semi-analytic models of afterslip, poroelastic rebound and viscoelastic flow. Geophysical Journal International, 182(3): 1124-1140.

Brace, W.F. and Kohlstedt, D.L., 1980. Limits on lithospheric stress imposed by laboratory experiments. Journal of Geophysical Research, 85(B11): 62486252.

Brun, J.P., 1999. Narrow rifts versus wide rifts: inferences for mechanics of rifting from laboratory experiments. Phil. Trans. R. Soc. Lond., 357: 695-712.

Buck, W.R., 1991. Modes of continental lithosphere extension. Journal of Geophysical Research, 96(B12): 20,161-20,178.

Bürgmann, R. and Dresen, G., 2008. Rheology of the Lower Crust and Upper Mantle: Evidence from Rock Mechanics, Geodesy, and Field Observations. Annual Review of Earth and Planetary Sciences, 36(1): 531-567.

Burov, E. B., 2010. The equivalent elastic thickness (Te), seismicity and the longterm rheology of continental lithosphere: Time to burn-out "crème brûlée"?: Insights from large-scale geodynamic modeling. Tectonophysics, 484(1-4): 426.

Burov, E. B. and Yamato, P., 2008. Continental plate collision, P-T-t-z conditions and unstable vs. stable plate dynamics: Insights from thermo-mechanical modelling. Lithos, 103(1-2): 178-204.

Crameri, F., Kaus, B.J.P., 2010. Parameters that control lithospheric-scale thermal localization on terrestrial planets. Geophysical Research Letters 37, L09308, doi:10.1029/2010GL042921.

Collettini, C., Niemeijer, A., Viti, C. and Marone, C., 2009. Fault zone fabric and fault weakness. Nature, 462: 907-911.

Déverchère, J., Petit, C., Gileva, N., Radziminovitch, N., Melnikova, V. and San'kov, V., 2001. Depth distribution of earthquakes in the Baikal rift system and its implications for the rheology of the lithosphere. Geophysical Journal International, 146: 714-730.

Drury, M.R., 2005. Dynamic recrystallization and Strain Softening of Olivine Aggregates in the Laboratory and the Lithosphere. Geological Society, London, Special Publications, 243: 127-142.

Faulkner, D.R., Jackson, C.A.L., Lunn, R.J., Schlische, R.W., Shipton, Z.K., Wibberley, C.A.J. and Withjack, M.O., 2010. A review of recent developments concerning the structure, mechanics and fluid flow properties of fault zones. Journal of Structural Geology, 32(11): 1557-1575.

Freed, A.M., Bürgmann, R. and Herring, T., 2007. Far-reaching transient motions after Mojave earthquakes require broad mantle flow beneath a strong crust. Geophysical Research Letters, 34.

Gerbi, C., Culshaw, N., Marsh, J., 2010. Magnitude of weakening during crustal-scale shear zone development. Journal of Structural Geology 32, 107-117

Goetze, C., 1978. The mechanisms of creep in olivine. Philosophical Transactions of the Royal Society London Series A, 288: 99-119.

Gratier, J.P. and Gueydan, F., 2007. Deformation in the presence of fluids and mineral reactions: Effect of fracturing and fluid-rocks interaction on seismic 
cycles. In: M. Handy, G. Hirth, J. Rice, N. Hovius and A. Friedrich (Editors), The Dynamics of Fault Zones. MIT Press, 95th Dahlem Conference.

Gueydan, F., Leroy, Y.M. and Jolivet, L., 2004. Mechanics of low-angle extensional shearzones at the brittle-ductile transition. Journal of Geophysical Research, 109: B12407, doi:10.1029/2003JB002806.

Gueydan, F., Leroy, Y.M., Jolivet, L. and Agard, P., 2003. Analysis of continental midcrustal strain localization induced by reaction-softening and microfracturing. Journal of Geophysical Research, 108(B2): 2064, doi:10.1029/2001JB000611.

Gueydan, F., Morency, C. and Brun, J.-P., 2008. Continental rifting as a function of lithosphere mantle strength. Tectonophysics, 460(1-4): 83-93.

Hirth, G. and Kohlstedt, D., 2003. Rheology of the Upper Mantle and the Mantle Wedge: A view from the Experimentalists. Geophysical Monographs, 138: 83105.

Holdsworth, R.E., 2004. PLANETARY SCIENCE: Enhanced: Weak Faults--Rotten Cores. Science, 303(5655): 181-182.

Huismans, R. S. and Beaumont, C., 2003. Symmetric and asymmetric lithospheric extension: Relative effects of frictional-plastic and viscous strain softening. Journal of Geophysical Research, 108(B10): 2496.

Jackson, J., 2002. Strength of the continental lithosphere: time to abandon the jelly sandwich? GSA Today, September: 1-9.

Kaus, B.K.P., Podladchikov, Y.Y., 2006. Initiation of localized shear zones in viscoplastic rocks. Journal of Geophysical Research 111, B04412, doi:10.1029/2005JB003652.

Kronenberg, A.K., Kirby, S.H. and Pinkston, J., 1990. Basal slip and mechanical anisotropy of biotite. Journal of Geophysical Research, 95(B12): 19,25719,278 .

Lavier, L.L. and Buck, W.R., 2002. Half graben versus large-offset low-angle normal fault: importance of keeping cool during normal faulting. Journal of Geophysical Research, 107(B2).

Lindsey, E. O. and Fialko, Y., 2013. Geodetic slip rates in the southern San Andreas Fault system: Effects of elastic heterogeneity and fault geometry. Journal of Geophysical Research, 118(2): 689-697.

Luan, F.C. and Paterson, M.S., 1992. Preparation and deformation of synthetic aggregates of quartz. J. Geophys. Res., 97(B1): 301-320.

Maggi, A., Jackson, J.A., Priestley, K. and Baker, C., 2000. A reassessment of focal depth distributions in southern Iran, the Tien Shan and northern India: Do earthquakes really occur in the continental mantle? Geophysical Journal International, 143: 629-661.

Montési, L.G.J., Zuber, M.T., 2002. A unified description of localization for application to large-scale tectonics. Journal of Geophysical Research 107, 2045, doi:10.1029/2001JB000465.

Montési, L.G.J., 2007. A constitutive model for layer development in shear zones near the brittle-ductile transition. Geophysical Research Letters, 34.

Montési, L.G.J., 2013. Fabric development as the key for forming ductile shear zones and enabling plate tectonics. Journal of Structural Geology, 50(0): 254-266.

Nadeau, R.M. and Dolenc, D., 2005. Nonvolcanic Tremors Deep Beneath the San Andreas Fault. Science, 307(5708): 389. 
Nadeau, R.M. and Guilhem, A.I., 2009. Nonvolcanic Tremor Evolution and the San Simeon and Parkfield, California, Earthquakes. Science, 325(10 July): 191193.

Nagel, T.J. and Buck, W.R., 2004. Symmetric alternative to asymmetric rifting models. Geology, 32(11): 937-940.

Park, Y., S.-H. Yoo, and J.-H. Ree, 2006. Weakening of deforming granitic rocks with layer development at middle crust, Journal or Structural Geology 28, 919-928. doi:10.1016/j.jsg.2006.02.005.

Platt J. P., Behr, W. M., 2011. Grainsize evolution in ductile shear zones: Implications for strain localization and the strength of the lithosphere. Journal of Structural Geology 33, 537- 550, doi:10.1016/j.jsg.2011.01.018.

Poirier, J.-P., 1980. Shear localization and shear instability in materials in the ductile field. Journal of Structural Geology 2, 135- 142.

Précigout, J. and Gueydan, F., 2009. Mantle weakening and strain localization: Implications for the long-term strength of the continental lithosphere. Geology, 37(2): 147-150.

Précigout, J., Gueydan, F., Gapais, D., Garrido, C.J. and Essaifi, A., 2007. Strain localisation in the subcontinental mantle - a ductile alternative to the brittle mantle. Tectonophysics, 445(3-4): 318-336.

Regenauer-Lieb, K., Yuen, D., 2004. Positive feedback of interacting ductile faults from coupling of equations of state, rheology and thermal mechanics. Physics of the Earth and Planetary Interiors 142, 113- 135.

Rolandone, F., Bürgmann, R. and Nadeau, R.M., 2004. The evolution of the seismicaseismic transition during the earthquake cycle: Constraints from the timedependent depth distribution of aftershocks. Geophysical Research Letters, 31(L23610).

Sawyer, D.S., 1985. Brittle failure in the Upper Mantle during extension of continental lithosphere. Journal of Geophysical Research, 90: 3021-3025.

Schueller, S., Gueydan, F. and Davy, P., 2005. Brittle-ductile coupling: Role of ductile viscosity on brittle fracturing. Geophysical Research Letters, 32(L10308): doi:10.1029/2004GL022272.

Schueller, S., Gueydan, F. and Davy, P., 2010. Mechanics of the transition from localized to distributed fracturing in layered brittle-ductile systems. Tectonophysics, 484(1-4): 48-59.

Shelton, G., 1981. Experimental flow laws for crustal rocks. EOS, 62(17): 396.

Shelly, D. R. and Hardebeck, J. L., 2010. Precise tremor source locations and amplitude variations along the lower-crustal central San Andreas Fault. Geophysical Research Letters, 37: L14301.

Sullivan, W.A., A.S. Boyd, M.E. Monz, 2013. Strain localization in homogenous granite near the brittle-ductile transtiion: A case study of the Kellyland fault zone, Maine, USA, Journal or Structural Geology 56, 70-88. doi:10.1016/j.jsg.2013.09.003

Thatcher, W. and Pollitz, F.F., 2008. Temporal evolution of continental lithospheric strnegth in actively deforming regions. GSA Today, 18(4/5): 4-11.

Thielmann, M. and Kaus, B.J.P., 2012. Shear heating induced lithospheric-scale localization: Does it result in subduction? Earth and Planetary Science Letters, 359,Äì60(0): 1-13.

Thomas, A.M., Nadeau, R.M. and Bürgmann, R., 2009. Tremor-tide correlations and near-lithostatic pore pressure on the deep San Andreas fault Nature, 462: 1048-1051. 
Thomas, A. M., Bürgmann, R., Shelly, D. R., Beeler, N. M. and Rudolph, M. L., 2012. Tidal triggering of low frequency earthquakes near Parkfield, California: Implications for fault mechanics within the brittle-ductile transition. Journal of Geophysical Research, 117: B05301.

Tommasi, A., Knoll, M., Vauchez, A., Signorelli, J.W., Thoraval, C. and Logé, R., 2009. Structural reactivation in plate tectonics controlled by olivine crystal anisotropy. Nature Geosciences, 2(June 2009): 423-427.

Toy, V., Newman, J., Lamb, W., Tikoff, B, 2010. The role of pyroxenites in formation of shear instabilities in the mantle: evidence from an ultramafic ultramylonite, Twin Sisters Massif, Washington. Journal of Petrology 51, 55- 80.

Vauchez, A., Tommasi, A. and Mainprice, D., 2012. Faults (shear zones) in the Earth's mantle. Tectonophysics, 558-559: 1-27.

Warren, J.M. and Hirth, G., 2006. Grain size sensitive deformation mechanisms in naturally deformed peridotites. Earth and Planetary Science Letters, 248(1-2): 423-435.

White, S. H., Burrows, S.E., Carreras, J., Shaw, N.D., Humphreys, F.J., 1980. On mylonites in ductile shear zones. Journal of Structural Geology 2, 175- 187.

Wilks, K.R. and Carter, N.L., 1990. Rheology of some continental lower crustal rocks. Tectonophysics, 182: 57-77.

Wintsch, R.P., Christoffersen, R. and Kronenberg, A.K., 1995. Fluid-rock reaction weakening of fault zones. Journal of Geophysical Research, 100(B7): 13,02113,032 . 
Figure caption
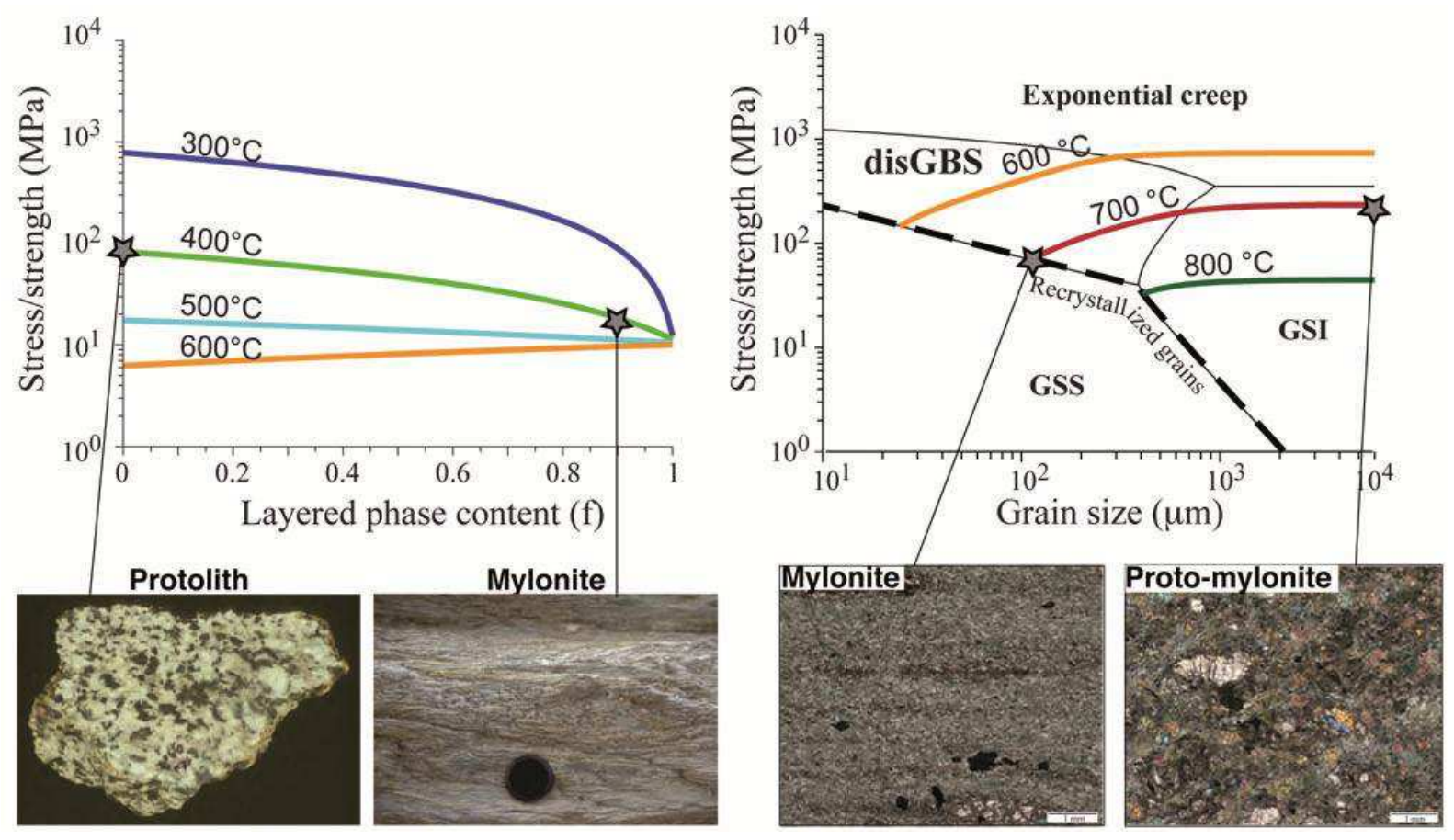

Figure 1: Field observation in naturally deformed rocks allowing the definition of weakening mechanisms. A) In the mid-crust, an increase in the fraction of rock that has a layered fabric from $f=0$ in the protolyth to $f=0.9$ in the mylonite (phyllonite) defines weakening that is expected at temperature less than $500^{\circ} \mathrm{C}$. B) In the mantle, grain size reduction from $1 \mathrm{~cm}$ in the protolith to $100 \mu \mathrm{m}$ or less in a mylonite leads to significant weakening at temperatures less than $800^{\circ} \mathrm{C}$, where deformation is accommodated by disGBS. All the curves are shown for a constant strain rate of $10^{-}$ ${ }^{15} \cdot \mathrm{S}^{-1}$ 


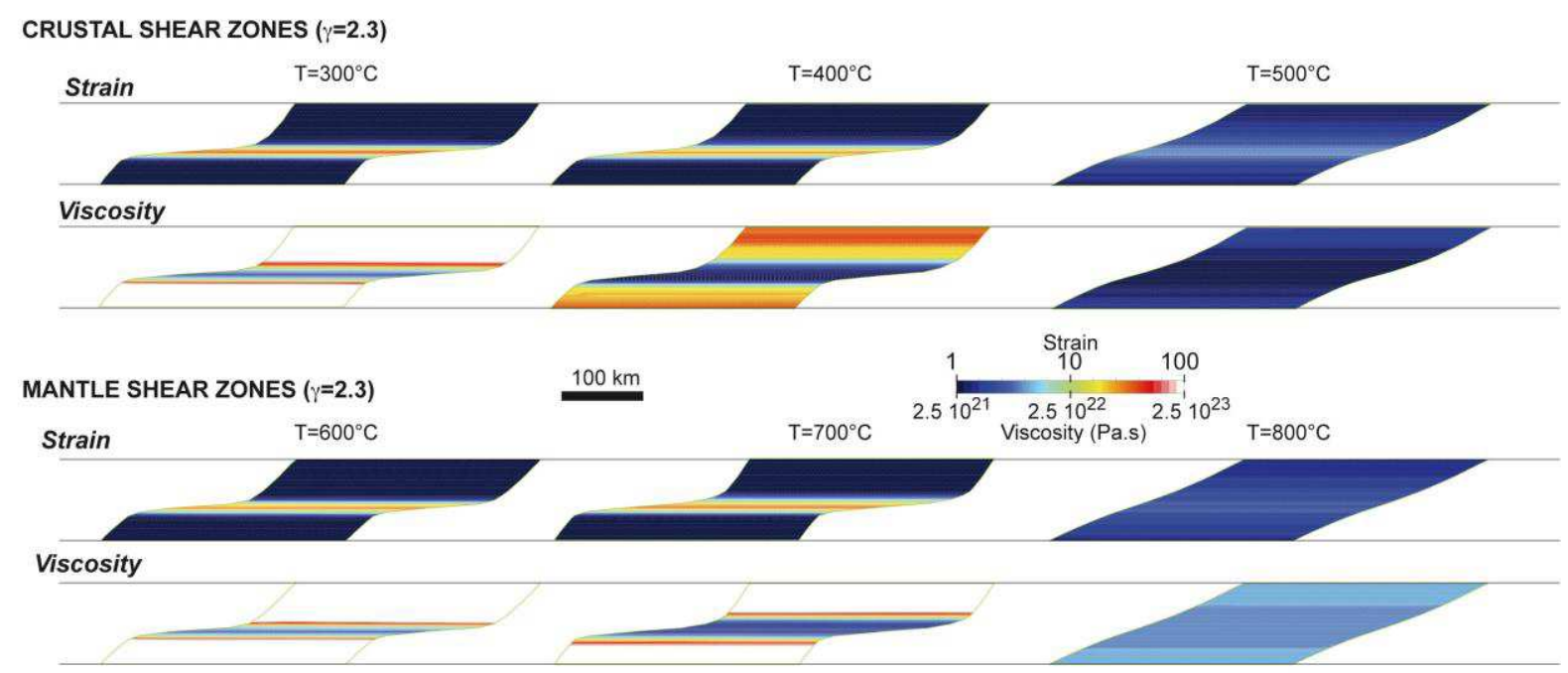

Figure 2: 1D large strain simple shear numerical experiments, shown in 2D to ease of reading, Deformation profile of horizontal pieces of the crust (top) or the mantle (bottom) undergoing simple shear to a strain of 2.3 at various temperature. The colors represent local strain and viscosity. Deformation localizes at temperature less than $500^{\circ} \mathrm{C}$ in the crust and $800^{\circ} \mathrm{C}$ in the mantle, locally reaching a strain of 100.

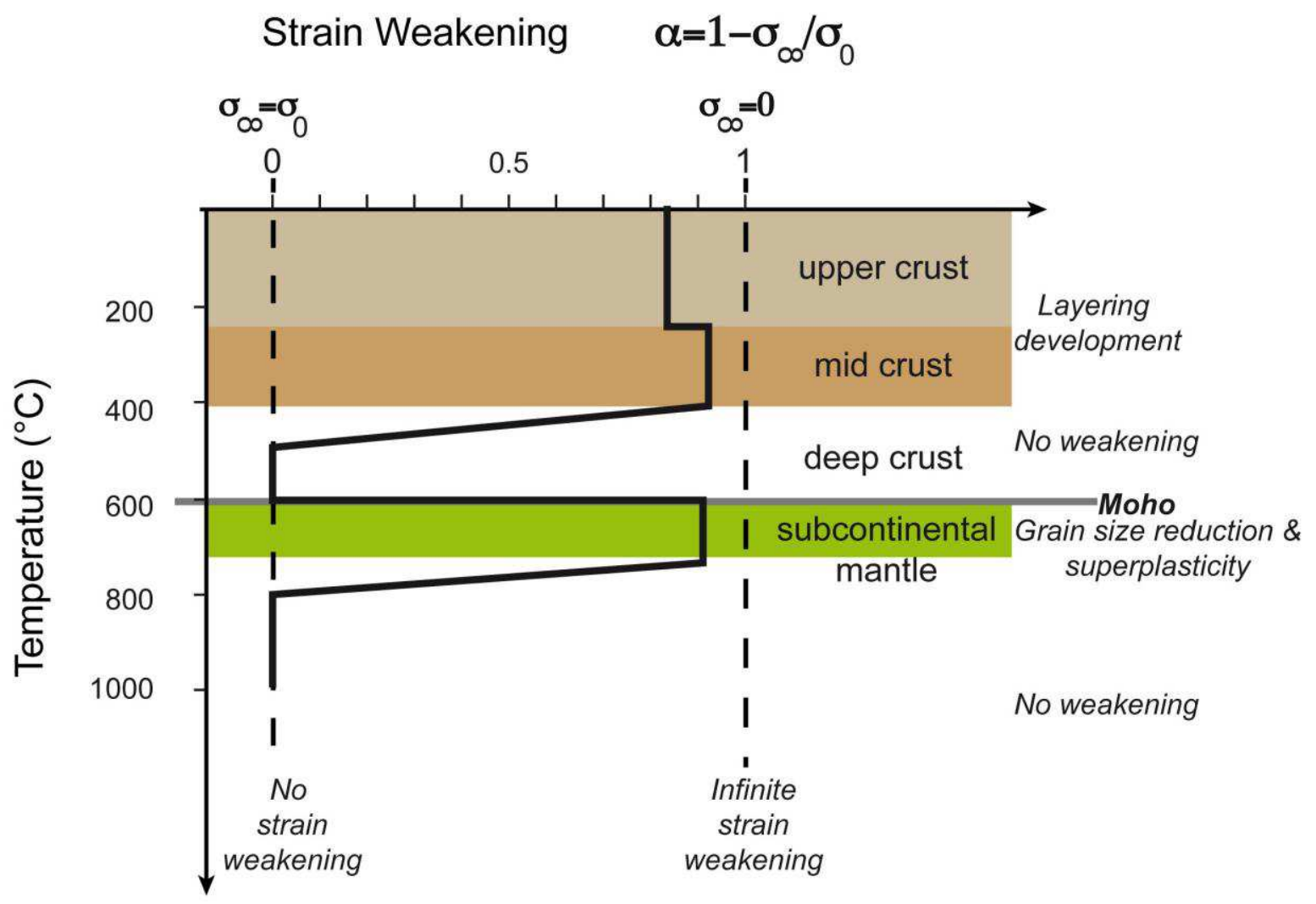


Figure 3: Evolution of effective viscosity during large strain experiment (inset and Fig. 2) of a piece of the crust (A) or the mantle (B) undergoing simple shear to a strain of 2.3 at various temperatures.

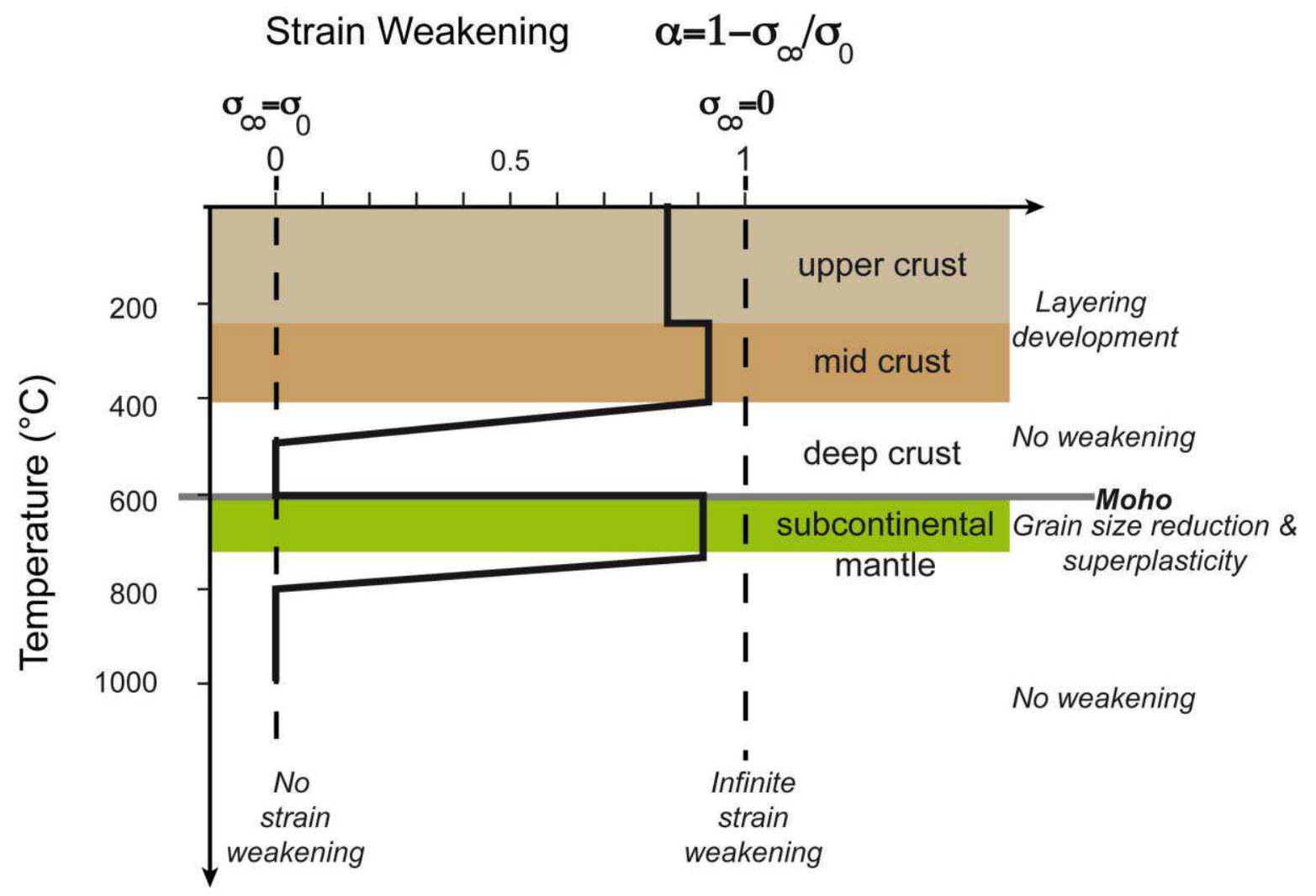

Figure 4: Strain weakening quantified by large strain experiments (Figs 2-3) as a function of depth/temperature across the continental lithosphere. Light brown, dark brown and green boxes highlight weakening in respectively the upper crust, the midcrust and the subcontinental mantle. 

A/ Low strain rate
$\mathrm{B} /$ Medium strain rate
$\mathrm{C} /$ High strain rate
\& strain
\& strain
\& strain

Strength (MPa)

Strength (MPa)

Strength (MPa)

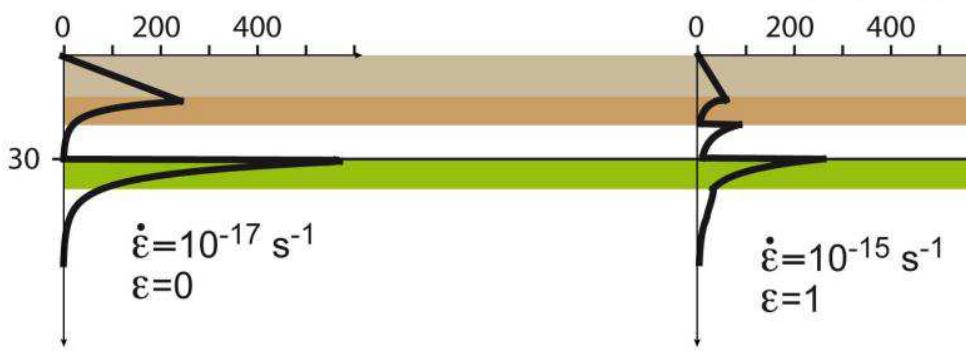

D/ Strain weakening enables continental plate tectonics
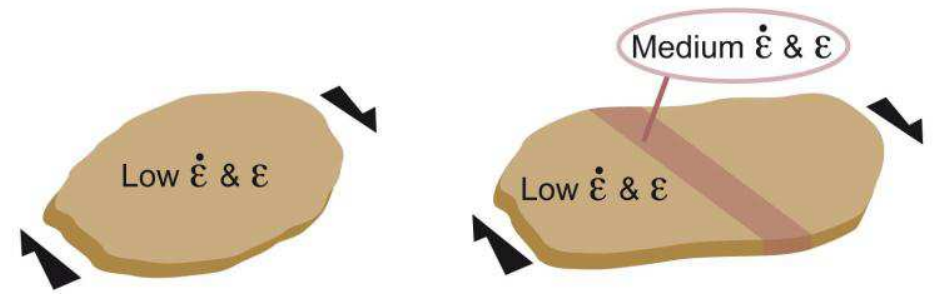

Weak

$\dot{\varepsilon}=10^{-13} \mathrm{~s}^{-1}$

$\varepsilon=2$

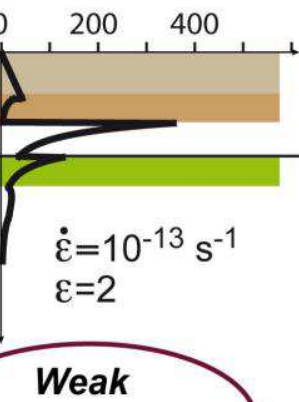

Plate boundaries

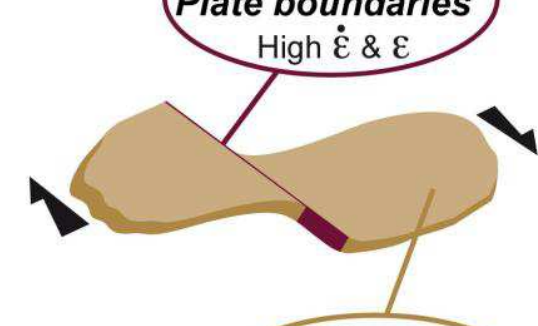

Low $\dot{\varepsilon} \& \varepsilon$

Progressive weakening and strain localization

Strong

Plate interiors

Low $\dot{\varepsilon} \& \varepsilon$

Figure 5: Three strength profiles for low (A), medium (B) and high (C) strain rate and strain exemplifying the positive feedback strain localization and weakening of the continental lithosphere. The relationship between strength, strain and strain rate is provided by eq. 3. Rheological parameters are given in Table 1. The continental geotherm is such that the Moho temperature at $30 \mathrm{~km}$ is $600^{\circ} \mathrm{C}$. Light brown, dark brown and green boxes highlight weakening in respectively the upper crust, the midcrust and the subcontinental mantle. D/ Schematic description of the role of strain weakening on continental plate tectonics: definition of both strong plate interiors (low strain rate/strain) and weak continental plate boundary (large strain rate/strain). 


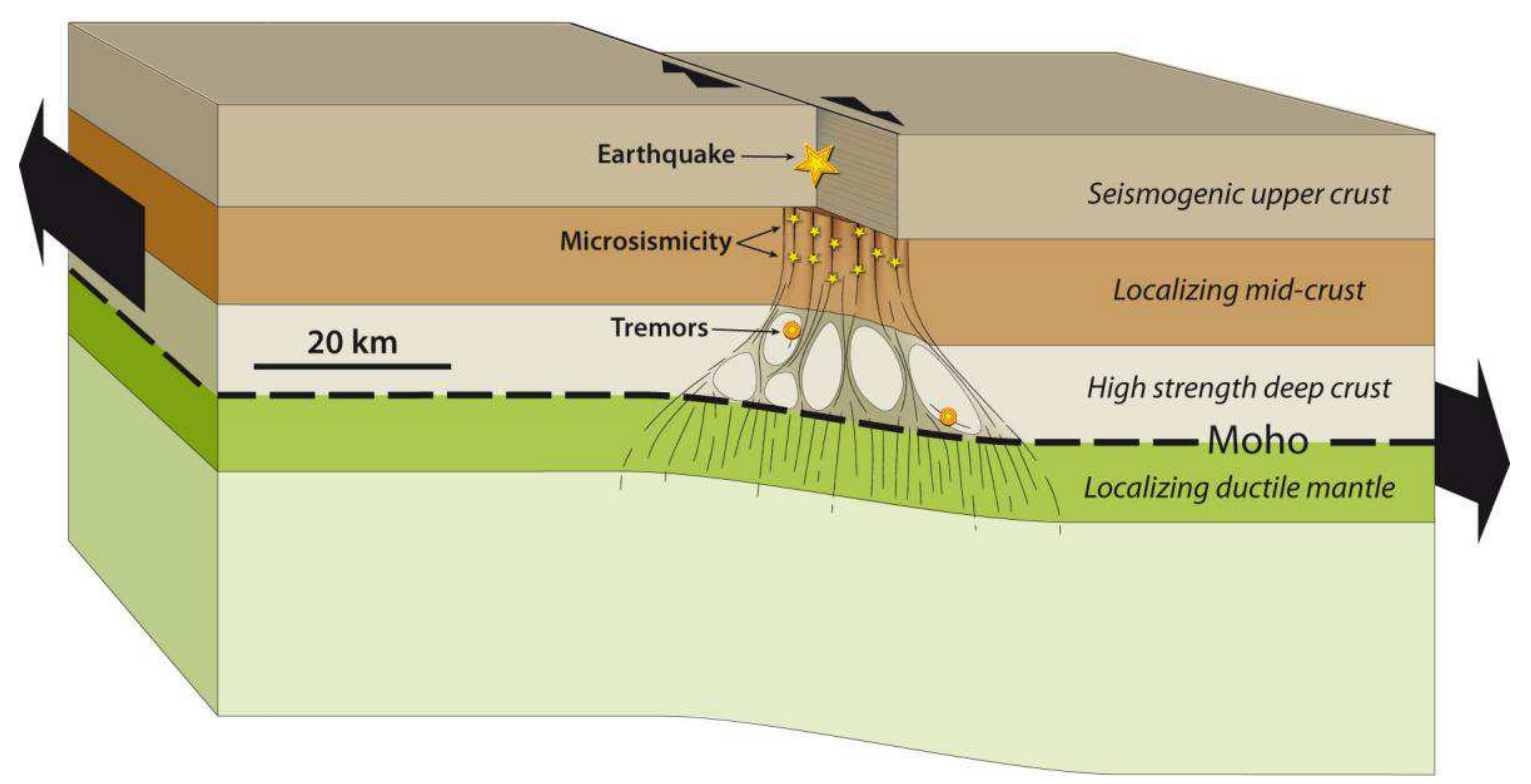

Figure 6: Schematic diagram of the mechanical layer of a continental strike-slip plate boundary showing, from top to bottom: the seismogenic upper crust; a weak, ductile mid-crust where deformation localizes unto ductile shear zones as the fraction of layered rock increases; a strong, ductile, lower crust where deformation does not localize spontaneously but where shear failure is possible due to transient loading and pore pressure increase; a weak upper mantle where grain size reduction localises deformation unto a $\sim 50 \mathrm{~km}$ wide ductile shear zone. 
Table 1: Rheological parameters used in this study

\begin{tabular}{|c|c|c|c|c|c|c|}
\hline & $\mathrm{A}\left(\mathrm{MPa}^{-\mathrm{n}} \cdot \mathrm{s}^{-1}\right)$ & $\begin{array}{l}\mathrm{Q}\left(\mathrm{kJ} . \mathrm{mol}^{-1}\right. \\
\left.{ }^{1}\right)\end{array}$ & $\mathrm{n}$ & $\mathrm{m}$ & $\tau_{\mathrm{p}}$ & References \\
\hline & $\begin{array}{l}\text { Pre- } \\
\text { exponential } \\
\text { constant }\end{array}$ & $\begin{array}{l}\text { Activation } \\
\text { energy }\end{array}$ & $\begin{array}{l}\text { Stress } \\
\text { exponent }\end{array}$ & $\begin{array}{l}\text { Grain size } \\
\text { exponent }\end{array}$ & $\begin{array}{l}\text { Goetze } \\
\text { constant }\end{array}$ & \\
\hline \multicolumn{7}{|c|}{ MANTLE (OLIVINE) RHEOLOGY } \\
\hline $\begin{array}{l}\text { Dislocation } \\
\text { Creep (r) }\end{array}$ & $1.110^{5}$ & 530 & 3.5 & - & - & \multirow[t]{3}{*}{$\begin{array}{l}\text { (Hirth and } \\
\text { Kohlstedt, 2003) }\end{array}$} \\
\hline $\begin{array}{l}\text { Diffusion } \\
\text { creep (d) }\end{array}$ & $1.510^{9}$ & 370 & 1 & 3 & - & \\
\hline $\begin{array}{l}\text { Dry-GBS } \\
\text { Creep (g) }\end{array}$ & $6.510^{3}$ & 400 & 3.5 & 2 & - & \\
\hline $\begin{array}{l}\text { Exponential } \\
\text { creep (e) }\end{array}$ & $5.710^{11} \mathrm{~s}^{-1}$ & 535 & 2 & - & 8500 & (Goetze, 1978) \\
\hline \multicolumn{7}{|c|}{ MID CRUST RHEOLOGY } \\
\hline $\begin{array}{l}\text { Quartz } \\
\text { Dislocation } \\
\text { Creep }\end{array}$ & $3.910^{-10}$ & 135 & 4 & - & - & $\begin{array}{l}\text { (Luan and } \\
\text { Paterson, 1992) }\end{array}$ \\
\hline $\begin{array}{l}\text { Feldspar } \\
\text { Dislocation } \\
\text { Creep }\end{array}$ & $3.210^{-4}$ & 238 & 3.2 & - & - & (Shelton, 1981) \\
\hline $\begin{array}{l}\text { Mica } \\
\text { Dislocation } \\
\text { Creep }\end{array}$ & $10^{-30}$ & 51 & 18 & - & - & $\begin{array}{l}\text { Biotite(Kronenberg } \\
\text { et al., 1990) }\end{array}$ \\
\hline \multicolumn{7}{|c|}{ DEEP CRUST RHEOLOGY } \\
\hline $\begin{array}{l}\text { Weak deep } \\
\text { crust } \\
\text { (granite) }\end{array}$ & \multicolumn{6}{|c|}{$\begin{array}{l}\text { Protolith rheology: } 50 \% \text { of feldspar, } 40 \% \text { of quartz, } 10 \% \text { of mica, following the } \\
\text { mixing flow laws (eq. } 3 \text {; section methods) }\end{array}$} \\
\hline $\begin{array}{l}\text { Strong deep } \\
\text { crust } \\
\text { (granulite) }\end{array}$ & $1.410^{4}$ & 445 & 4.2 & - & - & $\begin{array}{l}\text { Pikwitonei } \\
\text { granulite (Wilks } \\
\text { and Carter, 1990) }\end{array}$ \\
\hline
\end{tabular}

